\title{
MEASURING THE TECHNICAL AND COST EFFICIENCIES OF MAIZE FARMING IN THE NORTHERN REGION OF GHANA: DETERMINISTIC AND STOCHASTIC APPROACHES
}

\author{
Abdul-Basit Tampuli Abukari ${ }^{1 *}$ and Tuna Alemdar ${ }^{2}$ \\ ${ }^{1}$ Department of Agricultural and Resource Economics, Faculty of Agribusiness and Communication Sciences, \\ University for Development Studies, Tamale, Ghana. \\ ${ }^{2}$ Department of Agricultural Economics, Faculty of Agriculture, Cukurova University, 01330, Adana, Turkey \\ *corresponding author: tampulia@yahoo.com; atampuli@uds.edu.gh
}

\begin{abstract}
The study sets out to measure the technical, allocative and cost efficiencies of maize farming in the Northern Region of Ghana for the 2014-2015 farming season. The region has 73\% of its population as farmers, with maize being the most cultivated and consumed cereal. Stochastic Frontier Analysis (SFA) and Data Envelopment Analysis (DEA) are employed in the estimation. Interviews were conducted on 121 farmers selected through a mixed sampling technique. The study also segregated the quantities and prices of nitrogen and phosphorus from compound fertilizers. Under DEA, the study found an average efficiency of 79\%, 67\% and 53\% for technical, allocative and cost efficiencies respectively. For SFA the results respectively are $77 \%, 27 \%$ and 21\%. Cost and allocative efficiency estimates were very low especially for SFA. Using fractional regression analysis, it was found that household structure of farmers determined their technical efficiencies. Maize land size, marital status, education, and maize farming experience were found to affect allocative efficiency whiles marital status, household structure and maize farming experience affected cost efficiency. The study also found that labor was excessively used in the production process. Fertilizer application increased maize productivity more than other inputs. Policy recommendations were made following these findings.
\end{abstract}

Keywords: causes of inefficiency, data envelopment analysis, efficiency, fractional regression, ghana, maize, stochastic frontier analysis

http://dx.doi.org/10.21776/ub.agrise.2019.019.1.6

Received 15 November 2018

Accepted 21 January 2019

Available online 2 March 201

\section{INTRODUCTION}

In Ghana, agriculture employs $44.7 \%$ of the labor that contributes $21.9 \%$ to GDP (GSS, 2014). Ghana's economy has been growing steadily for the past few decades, with great regional disparities (Danquah \& Iddrisu, 2016). There is rising inequality manifested in the increasing Gini coefficient. The Northern Region witnessed the lowest reduction rate in poverty rate relative to the whole country, from 1992 to 2013 (Cooke et al., 2016). It is therefore plausible that agriculture should be the target in improving the conditions of the people in the region. Like all other agricultural improvement programs, productivity improvement is the starting point. A strategic crop is then chosen for the start. For the purpose of this study, we choose Northern Region as the research area because it has the largest proportion of its population as farmers in the whole country, who are mostly subsistent; 73\% (GSS 2012). It is also home to the highest number of extremely poor people since 2005 (GSS 2014). Even though Northern Region is not the highest producer of maize in Ghana, maize is the highest both in terms of planting area and output among cereal production in the region. Furthermore, maize is the 
highest in terms of household farming activities in the region. Nationally, maize is the most important cereal crop, representing about 55\% of total grain production. Over $90 \%$ of it is consumed as food, making it the most important crop for food security. It is also the major component in the feed of poultry and livestock (Akramov \& Malek 2011). Aside the main objective of measuring efficiency and productivity of maize farmers, the paper also seeks to explore various methodological gaps in the measurement of efficiency in Ghana. More importantly, findings are expected to generate policy recommendations.

Productivity is basically the ratio of output to input. Unlike productivity, efficiency compares all the Decision Making Unit (DMU) with a benchmark, which is normally the DMU with the highest productivity (Coelli et al., 2005). Put in another way, the efficient use of inputs automatically translates into increased productivity; hence the choice to use efficiency measurement for this study. The study further analyzes factors outside the control of farmers that affect the various efficiencies; technical, allocative and cost efficiencies (TE, AE, and CE). Technical efficiency measures the efficiency in converting inputs to outputs by producing with minimum inputs given output or obtaining the most output from a given input (Ramanathan 2003). The former reflects input saving (input oriented) whiles the latter is output augmenting (output oriented. In the presence of price information allocative and cost efficiencies are computed.

\section{RESEARCH METHODS}

\section{Material}

The variables are measured in different units. Nitrogen and phosphorous are measured in kilogram $(\mathrm{kg})$. Opportunity costs of maize land area and labor hours are used as an approximation of their prices. Maize output refers to the weight $(\mathrm{kg})$ of the harvested grains from the farm for that particular farming season. Maize land area is the total land area on which only the maize is cultivated. It is measured in acres (ac). There is no official rent charge for use of agricultural lands, however the common practice is to give a bag of maize on each acre if the land does not belong to the farmer. The price of maize in 2014 is therefore used as an approximation for the unit price agricultural land. Labor hours measure the amount of labor hours used in the process of producing the maize output. Labor is basically divided into two; family and hired labor. The information on the charges of hired labor for each activity was used to estimate that of the family labor. Machinery hours represent the number of hours machines are used on the farm for the production season. The main machine component of the production process is ploughing and sometimes, trucks for transporting produce. In the case of ploughing, the information was taken from the operators about the number of hours they spend in ploughing an acre of land. For the information on the cost, there is a fix amount tractor operators charge for ploughing an acre, however, the amount charged for transporting produce to the house differs from farmer to farmer. The total cost divided by the number of hours gives the per-unit price of machinery input.

The most commonly used chemical fertilizers for maize are the NPK (15-15-15) and NPK (23-10$5)$ compound fertilizers made up of nitrogen $(\mathrm{N})$, phosphorous $(\mathrm{P})$ and potassium $(\mathrm{K})$. Each bag of fertilizer is $50 \mathrm{~kg}$. The study segregated and measured quantities of individual elements and their unit prices in the compound fertilizer. Other studies like Chapoto and Sabasi et al. (2015), Ragasa and Chapoto (2017), Alemdar and Ören (2006) etc. segregated the nutrient quantities and not their unit price. While all soils in Ghana across the various ecological zones are sufficient in the $\mathrm{K}$ content, $\mathrm{N}$ and $\mathrm{P}$ vary considerably. In the specific case of the Northern Region, soils are relatively less acidic, fairly balanced in organic matter, lowest in nitrogen content, very low in phosphorous and lowest in calcium (FAO 2005). The segregation can be found in Appendix 1 . However, of interest to this study are $\mathrm{N}$ and $\mathrm{P}$, as $\mathrm{K}$ component is in abundance in Ghanaian soils, coupled with the fact that it fixes in the soil for a long time (Rosen et al., 2008).

The pesticide variable consists of all chemicals used for the control of weeds, insects, fungi, rodents and others. However, its measurements in terms of quantity and unit price is very difficult because they come in different forms; liquid, powder, grains etc. these are measured in liters, grams, packets etc. This makes the unit of measurement difficult. In light of this, the study considered weedicides which is predominantly used by farmers at some selected stages of production.

In order to avoid scale advantage among farmers coupled with the fact that maize land area is fixed in the short-run, all variables are converted to per unit acre. The study assumes a Variable Returns to Scale (VRS), which would be tested 
against the hypothesis that it exhibits a Constant Returns to Scale (CRS). The inefficiency effect variables otherwise known as environmental variables are: extension contacts, maize land size (small scale: below $5=0$, large scale: above $5=1$ ), education (literates $=0, \quad$ illiterates $=1$ ), gender (male $=0$, female $=1$ ), marital status (married $=0$, single $=1$ ), household structure (extended $=0$, nuclear=1), maize farming experience (below $15=0$, above $15=1$ ).

The sample was selected from the maize farmers in the Northern region using a multi-staged sampling technique. Using the optimal sample allocation, 10 districts were selected randomly from the 20. The Neyman's rule is then used to allocate the appropriate number to each sample. The list of 121 farmers was then selected from the list of farmers obtained from the agricultural district offices.

\section{Methodology}

The study employed DEA and SFA in the analysis of the data. While the former constructs the frontier using mathematical programming, the latter constructs the frontier using the econometric techniques (Coelli et al., 2005). Unlike DEA, deviation from the SFA frontier is divided into two; a two-sided symmetric random error that accounts for statistical noise (v) and the one-sided inefficiency (u) term. These two techniques have relative strengths and weaknesses over each other. The SFA has the ability separate noise from inefficient effects, while DEA combines them as inefficiency. As an econometric approach, hypothesis tests are possible subject to assumptions. It is also less sensitive to outliers in data, unlike DEA (Hjalmarsson et al., 1996; Sharma et al., 1999). DEA has the advantage of allowing data to freely construct frontier without any assumption. Authors like Silva et al. (2013) have argued that SFA is better for analysis that is highly characterized by stochastic elements like agriculture. However, there is no agreement on which of the assumptions in SFA to be used, hence the advantage of DEA over SFA. In the light of these, both techniques are used on the same data and results compared. On the choice of orientation, the study focuses on input orientation as farmers are known to have control over inputs than outputs (Coelli et al., 2005)

Data Envelopment Analysis (DEA) Input oriented model; $\min \theta_{\mathrm{m}}$

Subject to;

$\sum_{n=1}^{N} y_{j n} \lambda_{n} \geq y_{j m} ; j=1,2,3, \ldots . J$

$\sum_{n=1}^{N} x_{i n} \lambda_{n} \leq \theta_{m} x_{i m} ; i=1,2,3, \ldots . I$

$\theta_{\mathrm{m}}$ is unrestricted (free)

When this model is optimized, the $\theta$ becomes the efficiency estimate while $\lambda$ becomes the weights of the DMUs involved. $\mathrm{y}$ and $\mathrm{x}$ represent the vector of outputs and inputs respectively.

Considering $\mathrm{p}$ as the unit price of inputs, the observed cost of production is given as:

$\sum_{\mathrm{n}=1}^{\mathrm{N}} p_{i n} x_{i n}=\mathrm{k}$

The linear programming below produces the economically efficient input combination.

$\min \sum_{\mathrm{n}=1}^{\mathrm{N}} p_{i n} x_{i n}^{*}=k^{*}$

Subject to;

$\sum_{\mathrm{n}=1}^{\mathrm{N}} x_{i n}^{*} \psi_{\mathrm{n}} \leq \mathrm{x}_{\mathrm{im}} ; \mathrm{i}=1,2,3 \ldots \ldots . \mathrm{I}$

$\sum_{n=1}^{N} y_{j n} \psi_{n} \geq y_{j m} ; j=1,2,3 \ldots \ldots \ldots J$

$\Psi$ represents the efficiency parameter for the least input combination.

The cost efficiency therefore is:

$C E=\sum_{\mathrm{n}=1}^{\mathrm{N}} p_{i n} x_{i n}^{*} / \sum_{\mathrm{n}=1}^{\mathrm{N}} p_{i n} x_{i n}=\frac{k^{*}}{k}$

Allocative efficiency is residually obtained from this relation;

$A E=\frac{C E}{T E}$

Both $\mathrm{CE}$ and $\mathrm{AE}$, like $\mathrm{TE}$, have their values ranging between 0 and 1 , where 1 means full efficiency. All these models would be analyzed using the Data Envelopment Analysis Program (DEAP Version 2.1).

Stochastic Frontier Analysis (SFA)

Whatever functional form and distributional assumption, the generalized stochastic production function is represented as;

$$
Y_{i}=f\left(X_{i} ; \beta_{i}\right)+\varepsilon_{i}
$$

Where $\varepsilon_{i}=v_{i}-u_{i}$

$Y_{i}$ is the quantity of maize output, $X_{i}$ are vector of inputs, $\beta_{i}$ is the parameters which represent the 
output elasticities of inputs employed, and $\varepsilon_{i}$ is the composed error term made up of the noise and the inefficiency term. The equation is estimated using maximum likelihood estimation techniques which produces the parameters $\left(\beta_{i}\right)$, farm specific inefficiencies and noises, as well as their various variances and the standard deviations. That is $u_{i} v_{i}$, $\sigma_{v}^{2}, \sigma_{u}^{2}, \sigma_{u}, \sigma_{v}$ and $\sigma^{2}$. From these, important statistics like the lambda $\left(\lambda=\sigma_{u} / \sigma_{v}\right)$, gamma $\left(\gamma=\sigma_{u}^{2} / \sigma^{2}\right), \quad \sigma^{2}=\sigma_{v}^{2}+\sigma_{u}^{2}$ and Log likelihood functions are estimated. Out of the 4 distributional assumptions (half-normal, exponential, truncated normal and gamma), the study rejected the third and fourth based on the preference of simpler restrictive half-normal and exponential distributions to the less restrictive truncated normal and gamma distributions. Furthermore, gamma distribution requires larger sample size to predict efficiently (Ritter \& Simar, 1997; Coelli et al., 2005). Ritter and Simar (1997) further argued that the choice between half-normal and exponential is inconsequential. In order to select one of them, we set up a hypothesis on the appropriateness of halfnormal. If affirmed, it would be used. Otherwise, exponential distribution would be used.

The inefficiency term estimated from this is output oriented and cannot be compared with the input oriented DEA estimates. However, it is important in the further estimation of the input oriented estimates. According to Singh et al., (2001), there are basically two main ways of estimating this; either the cost function is estimated directly or indirectly from an already estimated production function. While the former requires considerable variations in the input prices data, the latter does not. However, the latter do restrict the choice of production function to Cobb-Douglas since it is self-dual (Appendix 3). The study uses this approach since some of the price data are either fixed or lack considerable variation. Notwithstanding, a hypothesis test is conducted to ascertain the appropriateness of the Cobb-Douglas production function against the more flexible translog. To proceed with the standard cost efficiency decomposition techniques, Equation 9 must be adjusted for the noise component in the model, leaving it in the deterministic framework (Singh et al., 2001). That is, the noise component is subtracted from both sides of the model.

$$
\ln Y_{i}-v_{i}=\ln \widehat{Y}_{i}=f\left(X_{i} ; \beta_{i}\right)-u_{i}
$$

The technically efficient input vector $\left(X^{t}\right)$ is found by estimating the input combinations at which the production function $\left(\hat{Y}_{i}\right)$ is equal to the observed input ratios $\left(X_{1} / X_{k}=R_{1 k} \quad(k>1)\right)$; this requires solving them simultaneously (Sharma et al., 1999). These equations are presented in Appendix 2.

Each of the technically efficient input vector $\left(\mathrm{X}_{\mathrm{i}}^{\mathrm{t}}\right)$ from this solution in appendix 2 is then multiplied by the corresponding observed input prices for each farmer, and summed. This gives technically efficient total cost of production for each farmer. The difference between this total cost and observed total cost of production is accounted for by technical inefficiency. Therefore the ratio of this cost to the observed total cost gives input oriented technical efficiency.

$$
\begin{aligned}
& C_{i}=\sum_{k=1}^{k=K} X_{\mathrm{ik}}^{\mathrm{t}} * P_{i k} \\
& \sum_{k=1}^{k=K} X_{i k}^{t} * P_{i k} / \sum_{k=1}^{k=K} X_{i k} * P_{i k}=T E_{i}
\end{aligned}
$$

Evoking the duality principle, the production function in Equation 10 becomes;

$C_{i}=\mathrm{f}\left(\widehat{\mathrm{Y}}_{\mathrm{i}}, \mathrm{P}_{\mathrm{i}} ; \beta_{\mathrm{i}}\right)+\mathrm{u}_{\mathrm{i}}$

Where $C_{i}$ is the minimum cost of producing output $\widehat{Y}_{i}$ for the ith farmer; $P_{i}$ as already defined is the vector of input prices. In order to estimate the cost efficiency, the economically efficient input combination (conditional input demand functions) is calculated. This is done by applying Shephard's lemma, which is, differentiating the cost function with respect to individual input prices. The individual conditional input demand functions are given in Appendix 4.

$\partial \mathrm{C}_{\mathrm{i}} / \partial \mathrm{P}_{\mathrm{k}}=\mathrm{X}_{\mathrm{dk}}=\mathrm{X}_{\mathrm{k}}^{\mathrm{c}}\left(\mathrm{P}_{\mathrm{k}}, \widehat{\mathrm{Y}}_{\mathrm{i}}, \delta\right)$

$\mathrm{X}_{\mathrm{dk}}=$ conditional input demand function,

$\mathrm{X}_{\mathrm{k}}^{\mathrm{c}}=$ cost/economically efficient input quantity

When these economically efficient input combinations are multiplied by their respective observed prices $\left(P_{k}\right)$ and summed, the results is economically or cost efficient cost of production. The difference between this and the observed cost of production is the results of inefficiency in cost of production. Therefore input oriented cost efficiency is the ratio of the economically efficient cost of production to the observed cost of production.

The cost efficient cost is;

$C_{i}=\sum_{\mathrm{k}=1}^{\mathrm{k}=\mathrm{K}} \mathrm{X}_{\mathrm{ik}}^{\mathrm{c}} * \mathrm{P}_{\mathrm{ik}}$ 
$\sum_{\mathrm{k}=1}^{\mathrm{k}=\mathrm{K}} \mathrm{X}_{\mathrm{ik}}^{\mathrm{c}} * \mathrm{P}_{\mathrm{ik}} / \sum_{\mathrm{k}=1}^{\mathrm{k}=\mathrm{K}} \mathrm{X}_{\mathrm{ik}} * \mathrm{P}_{\mathrm{ik}}=\mathrm{CE}_{\mathrm{i}}$

efficiency is the product of technical and

Allocative efficiency $\left(\mathrm{AE}_{\mathrm{i}}\right)$ is derived from

the results of the input oriented technical and cost efficiencies. As explained earlier, cost

$\mathrm{AE}_{\mathrm{i}}=\frac{\mathrm{CE}_{\mathrm{i}}}{\mathrm{TE}_{\mathrm{i}}}=\left(\sum_{\mathrm{k}=1}^{\mathrm{k}=\mathrm{K}} \mathrm{X}_{\mathrm{ik}}^{\mathrm{c}} * \mathrm{P}_{\mathrm{ik}} / \sum_{\mathrm{k}=1}^{\mathrm{k}=\mathrm{K}} \mathrm{X}_{\mathrm{ik}} * \mathrm{P}_{\mathrm{ik}}\right) /\left(\sum_{\mathrm{k}=1}^{\mathrm{k}=\mathrm{K}} \mathrm{X}_{\mathrm{ik}}^{\mathrm{t}} * \mathrm{P}_{\mathrm{ik}} / \sum_{\mathrm{k}=1}^{\mathrm{k}=\mathrm{K}} \mathrm{X}_{\mathrm{ik}} * \mathrm{P}_{\mathrm{ik}}\right)$

$\mathrm{AE}_{\mathrm{i}}=\sum_{\mathrm{k}=1}^{\mathrm{k}=\mathrm{K}} \mathrm{X}_{\mathrm{ik}}^{\mathrm{c}} * \mathrm{P}_{\mathrm{ik}} / \sum_{\mathrm{k}=1}^{\mathrm{k}=\mathrm{K}} \mathrm{X}_{\mathrm{ik}}^{\mathrm{t}} * \mathrm{P}_{\mathrm{ik}}$

The study also conducted analysis that are remotely related to the efficiency analyses and could further deepen the discussion of the results. These are input slacks analysis, Input cost share and Input Allocative Efficiency Coefficient (IAEC). The IAEC is explained in Appendix 5.

\section{Causes of inefficiencies}

The traditional two staged approach involves regressing efficiency estimate against proposed environmental factors (Liu et al., 2016). The applications started with the standard linear models like ordinary, generalized and truncated leastsquared models. These were followed by the Tobit, ordered logit and probit models, and then fractional response models (FRM) (Gelan \& Muriithi, 2012). The standard linear models are inappropriate because efficiency estimates are in the form of fractions or proportions (Ramalho et al., 2010a). The Tobit regression became popular and widely accepted until Simar and Wilson (2007) who argued that censoring efficiency estimates between zero and one is questionable, coupled with the fact that efficiency estimates are not generated through a censoring process. Papke and Wooldridge's (1996) fractional model was eventually introduced by Hoff (2007) and McDonald (2009). However in comparison to already applied models, they both found it less superior to OLS. The application of fractional regression got grounded with the work of Ramalho et al. (2010a). They criticized the work of Hoff (2007) and McDonald (2009) as inadequate because they used only logit specification to the neglect of others.

Table 1. Functional forms and marginal effects for models used

\begin{tabular}{ccc}
\hline Specification & \multicolumn{1}{c}{ Model $=E(y / x)$} & Marginal effects $=\frac{\partial E(y / x)}{\partial x_{i}}$ \\
\hline OLS & $x \theta$ & $\theta_{i}$ \\
Tobit & {$\left[\Phi\left(\frac{1-x \theta}{\sigma}\right)-\Phi\left(-\frac{x \theta}{\sigma}\right)\right] x \theta$} & $\theta_{i}\left[\Phi\left(\frac{1-x \theta}{\sigma}\right)-\Phi\left(-\frac{x \theta}{\sigma}\right)\right]$ \\
& $-\sigma\left[\varnothing\left(\frac{1-x \theta}{\sigma}\right)-\emptyset\left(-\frac{x \theta}{\sigma}\right)\right]+1-\Phi\left(\frac{1-x \theta}{\sigma}\right)$ & \\
Logit & $e^{x \theta} / 1+e^{x \theta}$ & $G(x \theta)[1-G(x \theta)]$ \\
Probit & $\Phi(x \theta)$ & $e^{-x \theta} G(x \theta)$ \\
Loglog & $e^{-e^{-x \theta}}$ & $e^{x \theta}[1-G(x \theta)]$ \\
Cloglog & $1-e^{-e^{x \theta}}$ &
\end{tabular}

Even though much of the application of the fractional regression is still being explored, it has proven to be more efficient than the previous ones, hence our choice of it. Each efficiency estimates under both techniques are subjected to this. Even though the traditional models (OLS and Tobit) 
have been proven not to appropriately represent the Data Generation Process (DGP) that governs efficiency estimates, we are including them as a contingency incase none of the fractional regression models fits a particular efficiency estimate. Finally we considered the one-part model which assumes that the said environmental variables equally affect both efficient and inefficient farmers. The need for the alternative two-part model arises when there exist substantial amount of farmers operating on the most efficient frontier (Ramalho et al., 2010a). The DEA results recorded 17 percent technically efficient farmers while only 3 percent were recorded for both allocative and cost efficiencies. In essence, the study is testing four one-part standard FRM models (logit, probit, loglog and complementary loglog) in order to select the appropriate specification. Using some of the tests, a decision would be made between OLS and Tobit regression models when the tests fail to select any of the fractional regression models. These functional forms and their corresponding marginal effect are represented in Table 1.

For all the above mentioned models the following tests are applied where possible; the Ramsey's RESET test, Pregibon's (1980) Goodness of Link tests, Ramalho, Ramalho and Murteira's Goodness of Functional Form tests (GOFF1 and GOFF2) and Davidson and MacKinnon's non-nested $P$ test. The Ramsey RESET test has been used for a variety of purposes but Wooldridge (2016) asserts that any other use of this test aside for functional form misspecification is misplaced. It involves the refitting of the regression equation using the squares and other higher powers of the predicted values as auxiliary variables. The Prigibon's link test is widely considered an alternative to the RESET test. This test introduces two variables (a hat and a hat squared). The p-value of the hat squared is then used to make the decision (Jones et al., 2013). Ramalho et al., (2010b) proposed GOFF and P tests as better alternatives to the RESET test. This plethora of tests is necessary for comparison and validation of decisions. It also makes it possible to easily settle on the specification to use. The pvalues for all these test are expected to be insignificant if the model is properly specified.

\section{Statements of hypotheses}

The SFA allows for the testing of hypotheses based on certain assumptions. The null hypotheses to be tested are; 1 . No inefficiency in the model. 2. The Cobb-Douglas production function is appropriate as against the translog production function. 3. A simpler half-normal distribution is adequate 4 . The model is exhibiting constant returns to scale. The Log likelihood ratio test is used to make decisions on these hypotheses.

\section{RESULTS AND DISCUSSION Summary of data}

Table 2 reveals that the Coefficient of Variation $(\mathrm{COV})$, pesticide and labor variables varied most among farmers in the region. The variation in the labor hours is expected as most of the labor employed are family labor, which depends on the family size of the farmer. The unregulated and misapplication of chemicals could explain that of the pesticide variable.

Table 2. Summary of sampled data

\begin{tabular}{lrrrrrr}
\hline & $\begin{array}{c}\text { Output } \\
(\mathrm{kg} / \mathrm{ac})\end{array}$ & $\begin{array}{c}\text { Labor } \\
\text { hours/ac }\end{array}$ & $\begin{array}{c}\text { Machinery } \\
\text { hours/ac }\end{array}$ & $\begin{array}{c}\text { Nitrogen } \\
(\mathrm{N})(\mathrm{kg} / \mathrm{ac})\end{array}$ & $\begin{array}{c}\text { Phosphorus } \\
(\mathrm{P})(\mathrm{kg} / \mathrm{ac})\end{array}$ & $\begin{array}{c}\text { Pesticide } \\
\text { use }(1 / \mathrm{ac})\end{array}$ \\
\hline Mean & 526.97 & 178.84 & 4.42 & 18.55 & 8.69 & 1.03 \\
MIN & 117.25 & 52.00 & 1.00 & 7.50 & 3.33 & 0.20 \\
MAX & 1000.0 & 542.36 & 6.00 & 46.00 & 20.00 & 4.00 \\
STD DEV & 199.38 & 76.69 & 1.3 & 6.44 & 3.14 & 0.53 \\
COV & 37.84 & 42.88 & 29.42 & 34.74 & 36.14 & 51.37 \\
Median & 501.75 & 169.93 & 5.00 & 19.00 & 8.33 & 1.00 \\
Unit price (GHC) & 1.45 & 2.25 & 17.23 & 2.33 & 3.56 & 11.22 \\
\hline
\end{tabular}




\section{Maximum Likelihood (ML) estimates for SFA}

Using NLOGIT 5.0. program, the ML estimates for the stochastic production function is summarized in Table 3. The coefficients which represent the output elasticities of the various inputs are all positive. This indicates that a percentage increase in any of them would increase productivity, keeping other inputs constant. However, the coefficients vary significantly. The fertilizer components would increase output more than twice as much as the other inputs. However, fertilizers with more nitrogen components would do much better. This finding would have been missing if the total weight of the compound fertilizer was considered instead. The higher output elasticity recorded for nitrogen stresses the need for more nitrogen to be applied in order to incase productivity of maize. Not only does it confirm the claim of the soil being deficient in nitrogen (FAO, 2005), it is consistent with the findings of Chapoto et al. (2015) and Ragasa and Chapoto (2017). However, consistent with the law of diminishing marginal productivity, these authors have warn against increasing nitrogen beyond the point it would have negative effect on maize output. Labor variable is the lowest and the only statistically insignificant coefficient.

Table 3. Stochastic frontier functions for maize production: half-normal distribution

\begin{tabular}{lcrrr}
\hline \multicolumn{1}{c}{ Variable } & Parameter & Coefficient & \multicolumn{1}{c}{ Std. Err } & Z-Statistic \\
\hline Constant & $\beta_{0}$ & $4.546^{\mathrm{a}}$ & 0.324 & 14.043 \\
Ln (Labor) & $\beta_{1}$ & 0.013 & 0.052 & 0.247 \\
Ln (Machinery) & $\beta_{2}$ & $0.137^{\mathrm{a}}$ & 0.065 & 2.110 \\
Ln (Nitrogen) & $\beta_{3}$ & $0.387^{\mathrm{a}}$ & 0.132 & 2.924 \\
Ln (Phosphorous) & $\beta_{4}$ & $0.261^{\mathrm{a}}$ & 0.130 & 2.010 \\
Ln (Pesticide) & $\beta_{5}$ & $0.142^{\mathrm{a}}$ & 0.049 & 2.893 \\
RTS $\left(\sum \beta_{i}\right)$ & & 0.94 & & \\
Lambda $\left(\sigma_{\mathrm{u}} / \sigma_{\mathrm{v}}\right)$ & $\lambda$ & $1.961^{\mathrm{a}}$ & 0.383 & 5.121 \\
Gamma $\left(\sigma_{\mathrm{u}}^{2} / \sigma^{2}\right)$ & $\gamma$ & $0.794^{\mathrm{a}}$ & 0.113 & 6.91 \\
Log likelihood & LLH & -4.744 & & \\
\hline
\end{tabular}

${ }^{a}$ Significant at 0.05 significance level

According the RTS statistic, maize farmers are operating under Decreasing Returns to Scale (DRS). The statistical significance of the lambda ( $\lambda$ ) statistic signifies the present of output oriented technical inefficient in the production of maize. The significant gamma statistic further reveals that much of the variations from the deterministic frontier are explained by technical inefficiency in maize production.

The results of the hypotheses tests are presented in Table 4. The first hypothesis, which confirms the status of lambda fairly reject the null hypothesis that there is no technical inefficiency in the production function. The second accepted the Cobb-Douglas production as the most appropriate representation of the production function. This decision adds more weight to our choice of model, but not the reason for its selection. The third hypothesis accepted the appropriateness of halfnormal distribution of the inefficiency term.

Table 4. Results of hypotheses tests

\begin{tabular}{llrrrr}
\hline \multicolumn{1}{c}{ Null Hypothesis } & \multicolumn{1}{c}{$\begin{array}{c}\text { LLHF } \\
(\mathrm{H} 0)\end{array}$} & \multicolumn{1}{c}{$\begin{array}{c}\text { LLHF } \\
(\mathrm{H} 1)\end{array}$} & $\begin{array}{r}\text { Test Statistic } \\
(\lambda)\end{array}$ & \multicolumn{1}{c}{$\begin{array}{c}\text { Critical value } \\
\left(\chi_{\mathrm{i}}^{2} 0.05\right)\end{array}$} & Decision \\
\hline $\mathrm{H}_{0}: \gamma=0$ & -7.242 & -4.744 & 4.997 & $\chi_{1}^{2} 0.05=3.841$ & Reject \\
$\mathrm{H}_{0}: \beta_{\mathrm{kj}}=0$ & -4.744 & 7.201 & 23.89 & $\chi_{15}^{2} 0.05=24.996$ & Accept \\
$\mathrm{H}_{0}: \delta_{0}=\delta_{1}=\delta_{2=\ldots .}=\delta_{8}=0$ & -4.744 & -4.287 & 0.914 & $\chi_{1}^{2} 0.05=3.841$ & Accept \\
$\mathrm{H}_{0}: \beta_{1}+\beta_{2}+\ldots \ldots+\beta_{5}=1$ & -4.995 & -4.744 & 0.501 & $\chi_{1}^{2} 0.05=3.841$ & Accept \\
\hline
\end{tabular}


The last hypothesis states that maize production in the region is exhibiting CRS. This means that the DRS found in the estimation is not significantly different from CRS. Like the second hypothesis, this also confirms our choice of return to scale.

Table 5. Summary of efficiency estimates

\begin{tabular}{lrrrrrr}
\hline Efficiency level (\%) & DEA-TE & SFA-TE & DEA-AE & SFA-AE & DEA-CE & \multicolumn{2}{c}{ SFA-CE } \\
\hline$<10$ & 0 & 0 & 0 & 0 & 0 & 5 \\
$\geq 10<19$ & 0 & 0 & 0 & 27 & 0 & 61 \\
$\geq 20<30$ & 0 & 0 & 1 & 55 & 2 & 41 \\
$\geq 30<40$ & 0 & 1 & 5 & 28 & 25 & 14 \\
$\geq 40<50$ & 1 & 2 & 16 & 9 & 27 & 0 \\
$\geq 50<60$ & 5 & 8 & 19 & 2 & 34 & 0 \\
$\geq 60<70$ & 29 & 20 & 22 & 0 & 16 & 0 \\
$\geq 70<80$ & 34 & 30 & 29 & 0 & 7 & 0 \\
$\geq 80<90$ & 15 & 51 & 22 & 0 & 5 & 0 \\
$\geq 90<100$ & 16 & 9 & 3 & 0 & 1 & 0 \\
100 & 21 & 0 & 4 & 0 & 4 & 0 \\
Mean & 0.79 & 0.77 & 0.67 & 0.27 & 0.53 & 0.21 \\
Minimum & 0.48 & 0.4 & 0.28 & 0.12 & 0.24 & 0.06 \\
Maximum & 1 & 0.95 & 1 & 0.53 & 1 & 0.4 \\
Std Dev & 0.14 & 0.12 & 0.16 & 0.09 & 0.16 & 0.07 \\
\hline
\end{tabular}

\section{Efficiency estimates}

The efficiencies from both techniques are presented in Table 5. The frequencies represent the number farmers in each efficiency ranking. The mean technical efficiencies from DEA and SFA are $79 \%$, and $77 \%$ respectively; $67 \%$ and $27 \%$, allocative efficiency for DEA and SFA respectively; $53 \%$ and $21 \%$, cost efficiency for DEA and SFA respectively.

Since DEA ascribes all deviations to inefficiency, it is expected that DEA TE estimates should be lower than that of SFA. This situation is expected when the DEA frontiers enveloped the data more tightly. Results from Alemdar and Ören (2006) also behaved the same way. According to Johansson (2005), this could also indicate the superiority of DEA results over SFA, as it is most likely an indication of functional misspecification under SFA. According to the results of hypothesis 2 , this could not be the case for this study since the chosen production is found to be appropriate. Since DEA results are expected to be sensitive to outliers, its presents could also explain this seeming anomaly. We therefore conducted a sensitivity analysis by estimating the efficiencies without outliers. The results show that, DEA estimates are not sensitive to outliers. Addai et al. (2014) and Shamsudeen et al. (2013) reported 0.72 and 0.74 respectively. Since these references employed SFA technique, it is only fair that this is compared to the SFA results of this study; 0.77 .

It can be observed from Table 5 that, $\mathrm{AE}$ and CE are generally low especially for SFA. The generally low estimates in the context of the study are expected in the sense that maize farmers in the region are generally subsistent, and do not see maize farming as a business, but an obligation to feed their families. This is supported by the finding that $100 \%$ percent of the farmers considered family consumption as the reason for farming maize, as against $19 \%$ who produced it for money. It is further supported by the fact that over $90 \%$ of maize produced in the region is consumed as food. Furthermore, Amanor-Boadu et al. (2015) in their Agricultural Production Survey of the region identified maize as one of the least commercialized crops. Another reason for the low estimated could be attributed to the uneconomic use and unsubstitutability of inputs, especially labor. This issue is investigated further by estimating the 
efficiencies without the labor variable. This saw a substantial improvement in the estimates. $\mathrm{AE}$ increased from 0.27 to 0.728 while CE increased from 0.21 to 0.60 . This assertion is supported by information from the sample data. Firstly, inputs that are found to be wasted in the production process should decrease $\mathrm{AE}$ and $\mathrm{CE}$ since they have a cost and input minimizing objective. The input slacks and IAEC in Table 6 show that labor is wasted in the production of maize. Secondly, since $\mathrm{AE}$ involves the substituting of inputs for one another, labor is expected to cause a low $\mathrm{AE}$ and $\mathrm{CE}$ since family labor is difficult to reallocate or substituted. Furthermore, authors like Ferrier and Lovell (1990) considers slacks as a form of allocative inefficiency. Since the labor variable has the largest amount of slacks, it is normal that it is responsible for the low AE. The huge cost share of labor could also explain this phenomenon.

\section{DEA and SFA results}

Some authors, who used these comparative techniques, express their confidence in one technique over the other when there seem to be contradictory results. Doing that defeats the essence of the comparative approach. Johansson (2005) for instance expressed confidence in his DEA results more than the SFA. The reason for this decision is the consistently higher DEA estimates which theoretically, should have been lower than the SFA estimates. This he attributed to the possibility misspecification of the production function used in the SFA. This study also found the same pattern. However, the appropriateness of the production function was tested and the result shows the specification was appropriate for the analysis. In a similar case of Singh et al. (2001), the SFA result was given priority over DEA because the result of the AE in DEA was much smaller than the SFA. They attributed this to outliers in the DEA analysis. A similar problem is encountered in this study. However, a sensitivity analysis showed that outliers were not the cause of the problem. Investigating each variable's influence on the estimates show that labor variable could be responsible in the case of this study. This study therefore concludes that, despite these differences, there is no sufficient evidence to trust one result over the other. This is because there seem to be enough evidence in the sample to explain these differences and abnormalities. Hjalmarsson et al. (1996) and Sharma et al. (1999) are few examples of studies despite considerable differences and sometime lower and negative rank correlation among estimates, they didn't disregard the results of one technique. Without justification to prefer one technique over the other, we conclude that TE ranges from $77 \%$ to $79 \%$, AE; $27 \%$ to $67 \%$, and CE; $21 \%$ to $53 \%$. Their averages can be used as point estimates.

The agreement or disagreement between the two techniques is tested by estimating the spearman ranked correlation coefficient. The paired t-test indicates whether the sample means from both techniques are statistically the same; all is rejected indicating they are all statistically different. With the exception of $\mathrm{TE}$, there is a fairly strong correlation between the estimates from both techniques; $0.37,0.72$ and 0.63 for $\mathrm{TE}, \mathrm{AE}$ and $\mathrm{CE}$ respectively. The null hypotheses that each of the combinations is independent are rejected

\section{Other analyses}

These analyses are summarized in Table 6. Input slacks measure the amount of inputs that is wasted. These slacks make farmers inefficient even if they are operating on the efficient frontier. It shows that labor is the most wasted input among all, whiles the fertilizer components are the least. The IAEC, indicates which input should be increased or decreased in order for farmers to make more revenue or income. Inputs with coefficients more than one are underutilized, and are expected be increased for increased revenue. The opposite effect is the case when the coefficient is below one. It can be observed from the table that labor is the only over utilized input and should be reduced whiles the rest should be increased. Labor commands about $68 \%$ of the total cost of production followed by machinery use.

Table 6. Summary results of other analyses

\begin{tabular}{llllll}
\hline & Labor & Machinery & Nitrogen & Phosphorus & Pesticide \\
\hline \% as slacks & 8.55 & 4.81 & 4.2 & 3.82 & 4.48 \\
IAEC & 0.03 & 1.43 & 6.74 & 6.36 & 10.1 \\
Input cost share & 0.683 & 0.145 & 0.087 & 0.062 & 0.023 \\
\hline
\end{tabular}




\section{Causes of inefficiency}

The $\mathrm{p}$ values for various specification tests are presented in Table 7. For SFA-TE, DEA-TE, SFA$\mathrm{AE}$ and SFA-CE estimates, all functional specifications are strongly accepted. Not even the $\mathrm{P}$ test could help make a decision except in one. This situation is not strange as the results in Table 3 of Ramalho et al. (2010a) exhibited the same phenomenon. In the absence of a justification for the selection of a functional form, we present the results of all the specification for these estimates, except SFA-CE. A look at the P test suggests a consistent rejection of the loglog form, hence the choice of all specifications except the loglog. In the case of DEA-AE, cloglog is accepted under the link test and further confirmed by the consistent acceptance when cloglog is the null hypothesis under the $\mathrm{P}$ test at $5 \%$ significance level. The case of DEA-CE presents a unique situation where there is total rejection by all models including the OLS and the Tobit model. At 5\% significance level, the $\mathrm{P}$ test could reveal some level of acceptance, which is contradictory and inconclusive. After tightening the significance level to $1 \%$, cloglog is revealed as the clear choice by all the five tests. Even though the effects of the environmental variables on each of the estimates would be explained by the selected specification, the results of all with their corresponding marginal effects (values in brackets) are presented in Table 8 . These estimations are done with the 3.4.2 version of $R$.

Table 8 summarizes the various regression analyses of the environmental variables. Extension contacts are found not to affect all the efficiencies for both DEA and SFA across all specifications. The maize land size variable recorded a negative coefficient indicating small scale farmers are more efficient for all the efficiencies under all the functional forms. However, those of TEs and SFA$\mathrm{CE}$ are not significant. The result of marital status variable is contradictory under TE for DEA and SFA, but recorded positive and significant coefficients for $\mathrm{AE}$ and $\mathrm{CE}$ under all specifications. This means farmers who are not married are more allocatively and cost efficient than those who are married. Farming experience also recorded contradictory results under TE, but significantly affects $\mathrm{AE}$ and CE. It shows that younger and less experienced maize farmers are more allocatively and cost efficient than older and experienced ones.

Household variable is positive and significant across all the efficiencies and specifications except for SFA-AE which is not significant. The result indicates that farmers in nuclear households are more efficient than those in extended family households. An explanation can be sort from the fact that farmers in the nuclear family system have more time and supervisory role on their farms than their counterparts in the extended family systems. Even though everyone is allowed to have their own private farms, they are obliged to participate in all the farming activities of the household as well as theirs.

The education variable shows that illiterates are more technically efficient than literates but less efficient in terms of AE and CE. Educated people are known to either have an alternative source of income or job searching. This makes them pay less attention to their farms, hence less technically efficient. This result is consistent with Anang, Bäckman et al. (2016). However, the literate farmers are better in terms of cost minimization as they keep and monitor their expenses on the farms. It is only under CE that the coefficient of the gender variable is not contradictory. However, only that of SFA is significant for all specifications. It indicates that women farm managers are more cost efficient than their male counterparts.

Table 7 and 8 reveal that both the few selected and their competing models fit the data almost the same. They all agree on signs and significance across all the efficiencies. The marginal effects and the $R^{2} s$ are equally similar across efficiencies, techniques and functional forms.

\section{Challenges and reasons for maize farming}

Farmers considered tractors, rainfall and input credit as the most pressing, and considered labor as less a problem to maize farmers in the region. This affirms the findings in the analysis that labor is in abundance. In terms of reasons for farming maize, farmers consider maize farming more of a social obligation to feed their families than making money out of it. This stresses the position of maize as an important food security and poverty alleviation crop for the people in the region. 
Table 7. p-values for the various Specification tests

\begin{tabular}{|c|c|c|c|c|c|c|c|c|c|c|c|c|c|c|c|c|c|c|}
\hline & \multicolumn{6}{|c|}{ SFA-TE } & \multicolumn{6}{|c|}{ SFA-AE } & \multicolumn{6}{|c|}{ SFA-CE } \\
\hline & $\mathrm{O}$ & $\mathrm{T}$ & $\mathrm{L}$ & $\mathrm{P}$ & LO & CL & $\mathrm{O}$ & $\mathrm{T}$ & $\mathrm{L}$ & $\mathrm{P}$ & LO & $\mathrm{CL}$ & $\mathrm{O}$ & $\mathrm{T}$ & $\mathrm{L}$ & $\mathrm{P}$ & LO & $\mathrm{CL}$ \\
\hline RESET & 0.97 & 0.94 & 0.8 & 0.59 & 0.95 & 0.31 & 0.57 & 0.85 & 0.77 & 0.75 & 0.69 & 0.82 & 0.09 & 0.12 & 0.15 & 0.14 & 0.12 & 0.17 \\
\hline Link & 0.89 & 0.87 & 0.82 & 0.61 & 0.96 & 0.32 & 0.62 & 0.61 & 0.80 & 0.79 & 0.74 & 0.85 & $0.05^{\mathrm{b}}$ & $0.05^{\mathrm{b}}$ & 0.17 & 0.16 & 0.16 & 0.18 \\
\hline GOFF-I & & & 0.79 & 0.59 & - & 0.31 & & & 0.76 & 0.74 & & 0.81 & & & 0.15 & 0.13 & & 0.16 \\
\hline \multirow{7}{*}{$\begin{array}{l}\text { GOFF-II } \\
\mathrm{P} \text { test } \\
(\mathrm{H} 1 / \mathrm{H} 0)\end{array}$} & & & 0.8 & 0.59 & 0.95 & - & & & 0.75 & 0.75 & 0.69 & & & & 0.14 & 0.14 & 0.12 & \\
\hline & $\mathrm{L} / \mathrm{P}$ & $\mathrm{L} / \mathrm{LO}$ & $\mathrm{L} / \mathrm{CL}$ & $\mathrm{P} / \mathrm{LO}$ & $\mathrm{P} / \mathrm{CL}$ & $\mathrm{LO} / \mathrm{CL}$ & $\mathrm{L} / \mathrm{P}$ & L/LO & $\mathrm{L} / \mathrm{CL}$ & $\mathrm{P} / \mathrm{LO}$ & $\mathrm{P} / \mathrm{CL}$ & $\mathrm{LO} / \mathrm{CL}$ & $\mathrm{L} / \mathrm{P}$ & $\mathrm{L} / \mathrm{LO}$ & $\mathrm{L} / \mathrm{CL}$ & $\mathrm{P} / \mathrm{LO}$ & $\mathrm{P} / \mathrm{CL}$ & $\mathrm{LO} / \mathrm{CL}$ \\
\hline & 0.88 & 0.7 & 1 & 0.45 & 0.72 & 0.69 & 0.73 & 0.56 & 0.87 & 0.59 & 0.93 & 0.97 & 0.13 & $0.1^{\mathrm{c}}$ & 0.17 & $0.1^{\mathrm{c}}$ & 0.19 & 0.21 \\
\hline & P/LO & $\mathrm{LO} / \mathrm{L}$ & $\mathrm{CL} / \mathrm{L}$ & $\mathrm{LO} / \mathrm{P}$ & $\mathrm{CL} / \mathrm{P}$ & CL/LO & P/LO & $\mathrm{LO} / \mathrm{L}$ & $\mathrm{CL} / \mathrm{L}$ & $\mathrm{LO} / \mathrm{P}$ & $\mathrm{CL} / \mathrm{P}$ & CL/LO & P/LO & $\mathrm{LO} / \mathrm{L}$ & $\mathrm{CL} / \mathrm{L}$ & $\mathrm{LO} / \mathrm{P}$ & $\mathrm{CL} / \mathrm{P}$ & CL/LO \\
\hline & 0.54 & 0.87 & 0.2 & 0.8 & 0.23 & 0.16 & 0.85 & 0.93 & 0.69 & 0.85 & 0.63 & 0.49 & 0.17 & 0.19 & 0.14 & 0.15 & 0.12 & $0.09^{c}$ \\
\hline & \multicolumn{6}{|c|}{ DEA-TE } & \multicolumn{6}{|c|}{ DEA-AE } & \multicolumn{6}{|c|}{ DEA-CE } \\
\hline & $\mathrm{O}$ & $\mathrm{T}$ & $\mathrm{L}$ & $\mathrm{P}$ & LO & $\mathrm{CL}$ & $\mathrm{O}$ & $\mathrm{T}$ & $\mathrm{L}$ & $\mathrm{P}$ & LO & $\mathrm{CL}$ & $\mathrm{O}$ & $\mathrm{T}$ & $\mathrm{L}$ & $\mathrm{P}$ & LO & $\mathrm{CL}$ \\
\hline RESET & 0.98 & 0.97 & 0.43 & 0.49 & 0.38 & 0.58 & 0.15 & 0.16 & $0.03^{b}$ & $0.04^{\mathrm{b}}$ & $0.02^{b}$ & $0.06^{\mathrm{c}}$ & $0.02^{\mathrm{b}}$ & $0.02^{b}$ & $0.01^{\mathrm{a}}$ & $0.01^{\mathrm{a}}$ & $0.01^{\mathrm{a}}$ & $0.02^{\mathrm{b}}$ \\
\hline Link & 0.99 & 0.80 & 0.44 & 0.50 & 0.39 & 0.59 & $0.09^{\mathrm{c}}$ & $0.05^{\mathrm{b}}$ & $0.06^{\mathrm{c}}$ & $0.07^{\mathrm{c}}$ & $0.05^{\mathrm{b}}$ & 0.102 & $0.01^{\mathrm{a}}$ & $0.01^{\mathrm{a}}$ & $0.01^{\mathrm{a}}$ & $0.02^{\mathrm{b}}$ & $0.01^{\mathrm{a}}$ & $0.03^{\mathrm{b}}$ \\
\hline GOFF-I & & & 0.42 & 0.49 & & 0.58 & & & $0.03^{\mathrm{b}}$ & $0.04^{\mathrm{b}}$ & & $0.06^{\mathrm{c}}$ & & & $0.01^{\mathrm{a}}$ & $0.01^{\mathrm{a}}$ & & $0.02^{\mathrm{b}}$ \\
\hline GOFF-II & & & 0.43 & 0.48 & 0.38 & & & & $0.03^{\mathrm{b}}$ & $0.04^{\mathrm{b}}$ & $0.02^{\mathrm{b}}$ & & & & $0.01^{\mathrm{a}}$ & $0.01^{\mathrm{a}}$ & $0.01^{\mathrm{a}}$ & \\
\hline \multirow[t]{4}{*}{$\begin{array}{l}\mathrm{P} \text { test } \\
(\mathrm{H} 1 / \mathrm{H} 0)\end{array}$} & $\mathrm{L} / \mathrm{P}$ & $\mathrm{L} / \mathrm{LO}$ & $\mathrm{L} / \mathrm{CL}$ & $\mathrm{P} / \mathrm{LO}$ & $\mathrm{P} / \mathrm{CL}$ & $\mathrm{LO} / \mathrm{CL}$ & $\mathrm{L} / \mathrm{P}$ & L/LO & $\mathrm{L} / \mathrm{CL}$ & $\mathrm{P} / \mathrm{LO}$ & $\mathrm{P} / \mathrm{CL}$ & $\mathrm{LO} / \mathrm{CL}$ & $\mathrm{L} / \mathrm{P}$ & $\mathrm{L} / \mathrm{LO}$ & $\mathrm{L} / \mathrm{CL}$ & $\mathrm{P} / \mathrm{LO}$ & $\mathrm{P} / \mathrm{CL}$ & $\mathrm{LO} / \mathrm{CL}$ \\
\hline & 0.54 & 0.35 & 0.72 & 0.32 & 0.66 & 0.75 & $0.04^{\mathrm{b}}$ & $0.02^{\mathrm{b}}$ & $0.07^{\mathrm{c}}$ & $0.02^{b}$ & $0.07^{\mathrm{c}}$ & $0.08^{\mathrm{c}}$ & $0.08^{\mathrm{c}}$ & $0.01^{\mathrm{a}}$ & $0.02^{b}$ & $0.01^{\mathrm{a}}$ & $0.02^{\mathrm{b}}$ & $0.02^{\mathrm{b}}$ \\
\hline & P/LO & $\mathrm{LO} / \mathrm{L}$ & $\mathrm{CL} / \mathrm{L}$ & $\mathrm{LO} / \mathrm{P}$ & CL/P & CL/LO & $\mathrm{P} / \mathrm{LO}$ & $\mathrm{LO} / \mathrm{L}$ & $\mathrm{CL} / \mathrm{L}$ & $\mathrm{LO} / \mathrm{P}$ & $\mathrm{CL} / \mathrm{P}$ & CL/LO & $\mathrm{P} / \mathrm{LO}$ & $\mathrm{LO} / \mathrm{L}$ & $\mathrm{CL} / \mathrm{L}$ & $\mathrm{LO} / \mathrm{P}$ & CL/P & CL/LO \\
\hline & 0.4 & 0.45 & 0.34 & 0.56 & 0.42 & 0.27 & $0.03^{b}$ & $0.04^{\mathrm{b}}$ & $0.03^{b}$ & $0.04^{\mathrm{b}}$ & $0.04^{\mathrm{b}}$ & $0.02^{b}$ & $0.07^{\mathrm{c}}$ & $0.01^{b}$ & $0.01^{\mathrm{a}}$ & $0.01^{\mathrm{b}}$ & $0.01^{\mathrm{a}}$ & $0.00^{\mathrm{a}}$ \\
\hline
\end{tabular}

a, b, and c subscripts represent statistical significance at $1 \%, 5 \%$ and $10 \%$ respectively.

O,T,L,P,LO and CL represent OLS, Tobit, logit, probit, loglog and cloglog respectively. 
Table 8. Estimation results for selected fractional regression models

\begin{tabular}{|c|c|c|c|c|c|c|c|c|c|c|c|c|}
\hline & \multicolumn{4}{|c|}{ SFA-TE } & \multicolumn{4}{|c|}{ SFA-AE } & \multicolumn{4}{|c|}{ SFA-CE } \\
\hline & $\mathrm{L}$ & $\mathrm{P}$ & LO & CL & $\mathrm{L}$ & $\mathrm{P}$ & LO & CL & $\mathrm{L}$ & $\mathrm{P}$ & LO & CL \\
\hline Intercept & $0.608 \mathrm{a}$ & $0.374 a$ & $0.840 \mathrm{a}$ & 0.032 & $-0.761 \mathrm{a}$ & $-0.472 a$ & $-0.134 b$ & $-0.959 a$ & $-1.322 \mathrm{a}$ & $-0.802 a$ & $-0.438 a$ & -1.446 \\
\hline \multirow[t]{2}{*}{ Extension } & 0.025 & 0.017 & 0.017 & 0.020 & -0.036 & -0.020 & -0.018 & -0.032 & -0.040 & -0.021 & -0.017 & -0.038 \\
\hline & (0.004) & $(0.005)$ & $(0.003)$ & $(0.007)$ & $(-0.007)$ & $(-0.007)$ & $(-0.006)$ & $(-0.007)$ & $(-0.007)$ & $(-0.006)$ & $(-0.005)$ & $(-0.007)$ \\
\hline \multirow[t]{2}{*}{ Maize land size } & -0.012 & -0.004 & -0.016 & 0.003 & $-0.156 c$ & $-0.091 c$ & $-0.082 c$ & $-0.136 c$ & -0.136 & -0.077 & -0.067 & -0.123 \\
\hline & $(-0.002)$ & $(-0.001)$ & $(-0.003)$ & $(0.001)$ & $(-0.030)$ & $(-0.030)$ & $(-0.029)$ & $(-0.031)$ & $(-0.022)$ & $(-0.022)$ & $(-0.022)$ & $(-0.023)$ \\
\hline \multirow[t]{2}{*}{ Education } & 0.042 & 0.027 & 0.032 & 0.029 & $-0.159 b$ & $-0.096 b$ & $-0.092 b$ & $-0.133 c$ & $-0.137 \mathrm{c}$ & $-0.080 \mathrm{c}$ & $-0.072 c$ & $-0.121 \mathrm{c}$ \\
\hline & $(0.007)$ & $(0.008)$ & $(0.006)$ & (0.009) & $(-0.031)$ & $(-0.031)$ & $(-0.032)$ & $(-0.030)$ & $(-0.022)$ & $(-0.023)$ & $(-0.023)$ & $(-0.022)$ \\
\hline \multirow[t]{2}{*}{ Gender } & -0.067 & -0.036 & -0.062 & -0.026 & $0.180 \mathrm{~b}$ & $0.108 \mathrm{~b}$ & $0.101 \mathrm{~b}$ & $0.153 b$ & $0.172 b$ & $0.096 \mathrm{c}$ & $0.080 \mathrm{c}$ & $0.157 \mathrm{~b}$ \\
\hline & $(-0.011)$ & $(-0.010)$ & $(-0.012)$ & $(-0.008)$ & $(0.035)$ & $(0.035)$ & $(0.036)$ & $(0.035)$ & $(0.028)$ & $(0.027)$ & $(0.026)$ & $(0.029)$ \\
\hline \multirow[t]{2}{*}{ Marital status } & 0.067 & 0.040 & 0.056 & 0.038 & $0.226 b$ & $0.136 \mathrm{~b}$ & $0.128 b$ & $0.192 \mathrm{a}$ & $0.215 b$ & $0.124 \mathrm{~b}$ & $0.110 \mathrm{~b}$ & $0.191 \mathrm{a}$ \\
\hline & $(0.011)$ & $(0.012)$ & $(0.011)$ & $(0.012)$ & $(0.044)$ & (0.044) & $(0.045)$ & $(0.044)$ & $(0.035)$ & $(0.035)$ & $(0.036)$ & $(0.035)$ \\
\hline Household & $0.993 \mathrm{a}$ & $0.582 \mathrm{a}$ & $0.866 \mathrm{a}$ & $0.531 \mathrm{a}$ & 0.004 & 0.002 & 0.000 & 0.005 & $0.300 \mathrm{a}$ & $0.170 \mathrm{a}$ & $0.146 a$ & $0.269 a$ \\
\hline structure & $(0.167)$ & $(0.169)$ & $(0.169)$ & $(0.170)$ & $(0.001)$ & $(0.001)$ & $(0.000)$ & $(0.001)$ & $(0.049)$ & $(0.048)$ & $(0.047)$ & $(0.050)$ \\
\hline \multirow[t]{2}{*}{ Experience } & 0.074 & 0.044 & 0.063 & 0.040 & $-0.358 \mathrm{a}$ & $-0.213 a$ & $-0.199 a$ & $-0.306 \mathrm{a}$ & $-0.312 \mathrm{a}$ & $-0.178 \mathrm{a}$ & $-0.154 a$ & $-0.279 a$ \\
\hline & (0.013) & $(0.013)$ & $(0.012)$ & $(0.013)$ & $(-0.070)$ & $(-0.070)$ & $(-0.070)$ & $(-0.070)$ & $(-0.051)$ & $(-0.051)$ & $(-0.050)$ & $(-0.051)$ \\
\hline \multirow[t]{3}{*}{ R2 } & 0.608 & 0.601 & 0.602 & 0.601 & 0.252 & 0.252 & 0.251 & 0.253 & 0.250 & 0.247 & 0.244 & 0.252 \\
\hline & \multicolumn{4}{|c|}{ DEA-TE } & \multicolumn{4}{|c|}{ DEA-AE } & \multicolumn{4}{|c|}{ DEA-CE } \\
\hline & $\mathrm{L}$ & $\mathrm{P}$ & $\mathrm{LO}$ & $\mathrm{CL}$ & $\mathrm{L}$ & $\mathrm{P}$ & $\mathrm{LO}$ & $\mathrm{CL}$ & $\mathrm{L}$ & $\mathrm{P}$ & LO & $\mathrm{CL}$ \\
\hline Intercept & 0.993 & 0.604 & 1.170 & 0.249 & $1.159 \mathrm{a}$ & $0.715 \mathrm{a}$ & 1.282 & 0.377 & $0.290 \mathrm{c}$ & $0.183 c$ & $0.583 \mathrm{a}$ & -0.159 \\
\hline \multirow[t]{2}{*}{ Extension } & 0.059 & 0.038 & 0.046 & 0.040 & 0.062 & 0.038 & 0.047 & 0.040 & 0.056 & 0.035 & 0.041 & 0.039 \\
\hline & $(0.009)$ & $(0.011)$ & (0.008) & (0.013) & (0.013) & $(0.013)$ & $(0.012)$ & $(0.014)$ & $(0.013)$ & $(0.013)$ & $(0.013)$ & (0.013) \\
\hline \multirow[t]{2}{*}{ Maize land size } & -0.179 & -0.107 & -0.155 & -0.099 & $-0.578 \mathrm{a}$ & $-0.356 a$ & $-0.458 \mathrm{a}$ & $-0.365 a$ & $-0.521 \mathrm{a}$ & $-0.324 a$ & $-0.362 \mathrm{a}$ & $-0.382 \mathrm{a}$ \\
\hline & $(-0.029)$ & $(-0.030)$ & $(-0.028)$ & $(-0.031)$ & $(-0.123)$ & $(-0.124)$ & $(-0.119)$ & $(-0.128)$ & $(-0.124)$ & $(-0.124)$ & $(-0.118)$ & $(-0.131)$ \\
\hline \multirow[t]{2}{*}{ Education } & $0.351 b$ & $0.205 b$ & $0.305 b$ & $0.184 b$ & $-0.312 b$ & $-0.193 b$ & $-0.245 b$ & $-0.202 b$ & -0.104 & -0.067 & -0.067 & -0.091 \\
\hline & $(0.056)$ & $(0.057)$ & $(0.055)$ & (0.058) & $(-0.066)$ & $(-0.068)$ & $(-0.064)$ & $(-0.071)$ & $(-0.025)$ & $(-0.026)$ & $(-0.022)$ & $(-0.031)$ \\
\hline \multirow[t]{2}{*}{ Gender } & 0.255 & 0.148 & 0.219 & 0.133 & -0.034 & -0.017 & -0.029 & -0.010 & 0.108 & 0.068 & 0.063 & 0.095 \\
\hline & $(0.041)$ & $(0.041)$ & $(0.040)$ & $(0.042)$ & $(-0.007)$ & $(-0.006)$ & $(-0.008)$ & $(-0.003)$ & $(0.026)$ & $(0.026)$ & $(0.021)$ & (0.033) \\
\hline \multirow[t]{2}{*}{ Marital status } & -0.046 & -0.019 & -0.048 & -0.007 & $0.388 \mathrm{~b}$ & $0.235 b$ & $0.320 \mathrm{~b}$ & $0.229 \mathrm{~b}$ & $0.273 \mathrm{c}$ & $0.170 \mathrm{c}$ & $0.202 \mathrm{c}$ & $0.188 \mathrm{c}$ \\
\hline & $(-0.007)$ & $(-0.005)$ & $(-0.009)$ & $(-0.002)$ & $(0.082)$ & $(0.082)$ & $(0.083)$ & $(0.080)$ & $(0.065)$ & $(0.065)$ & (0.066) & (0.064) \\
\hline \multirow{3}{*}{$\begin{array}{l}\text { Household } \\
\text { structure } \\
\text { Experience }\end{array}$} & $0.594 a$ & $0.344 \mathrm{a}$ & $0.520 \mathrm{a}$ & $0.305 \mathrm{a}$ & $0.231 \mathrm{c}$ & $0.142 \mathrm{c}$ & $0.179 \mathrm{c}$ & $0.147 \mathrm{c}$ & $0.436 \mathrm{a}$ & $0.271 \mathrm{a}$ & $0.305 a$ & $0.314 \mathrm{a}$ \\
\hline & $(0.095)$ & $(0.096)$ & (0.094) & (0.096) & $(0.049)$ & $(0.050$ & $(0.047)$ & $(0.052)$ & $(0.104)$ & $(0.104)$ & (0.099) & $(0.107)$ \\
\hline & $\begin{array}{l}-0.422 b \\
(-0.067)\end{array}$ & $\begin{array}{c}-0.239 b \\
(-0.066)\end{array}$ & $\begin{array}{l}-0.375 b \\
(-0.068)\end{array}$ & $\begin{array}{l}-0.204 b \\
(-0.064)\end{array}$ & $\begin{array}{c}-0.553 a \\
(-0.117)\end{array}$ & $\begin{array}{c}-0.341 \mathrm{a} \\
(-0.119)\end{array}$ & $\begin{array}{c}-0.436 a \\
(-0.114)\end{array}$ & $\begin{array}{c}-0.353 a \\
(-0.124)\end{array}$ & $\begin{array}{c}-0.625 \mathrm{a} \\
(-0.148)\end{array}$ & $\begin{array}{l}-0.390 \mathrm{a} \\
(-0.150)\end{array}$ & $\begin{array}{l}-0.436 a \\
(-0.142)\end{array}$ & $\begin{array}{l}-0.460 \mathrm{a} \\
(-0.157)\end{array}$ \\
\hline $\mathrm{R}^{2}$ & 0.221 & 0.222 & 0.220 & 0.223 & 0.311 & 0.313 & 0.304 & 0.321 & 0.440 & 0.440 & 0.427 & 0.452 \\
\hline
\end{tabular}

a, b, and c subscripts represent statistical significance at $1 \%, 5 \%$ and $10 \%$ respectively

L,P,LO and CL represent logit, probit, loglog and cloglog respectively. 


\section{CONCLUSIONS AND RECOMMENDATIONS}

Without preference for the results of one technique over the other, we conclude that TE ranges from $77 \%$ to $79 \%$, AE; $27 \%$ to $67 \%$, and $\mathrm{CE} ; 21 \%$ to $53 \%$. The generally low $\mathrm{AE}$ and $\mathrm{CE}$ are attributable to the non-business attitude towards maize farming, as well as the fact that family labor is difficult to reallocate in the production process. Illiterate farmers and farmers in nuclear households tend to be more technically efficient, hence more productive. Farmers with lesser family labor like small scale farmers, single farmers and less experienced farmers have $\mathrm{AE}$ and $\mathrm{CE}$ advantage than larger scale, married and experienced farmers. Literate farmers and those from nuclear households have $\mathrm{AE}$ and $\mathrm{CE}$ advantage over those who are illiterates and from extended families.

In terms of policy recommendation, labor application in maize production should be reduced. There is a strong case for this recommendation. Labor variable has the lowest output elasticity even though it is not significant. It also has the largest amount of slacks. Costwise, it is the highest burden on production cost. $\mathrm{AE}$ and $\mathrm{CE}$ significantly improved when labor content is withdrawn. The IAEC suggested the reduction of labor input as against the other inputs. Furthermore, labor is the least of farmers' challenges in the region, indicating its abundance. Despite this recommendation, reducing family labor is challenging. In the short term, farmers can introduce on-farm complementary jobs to maize production, like bee keeping, animal rearing etc. In the long term, government should create employment opportunities to absorb this excess labor. Since the region is the second largest in terms of average number of people per household, birth control measures is another long term measure to reduce the family size. Increasing educational infrastructure is another way of reducing the labor content in production process.

The TE advantage illiterate farmers have over literates farmers suggest that when maize farming is combined with other off farms jobs, TE reduces. Also, farmers in the extended family system should synchronize their activities or consolidate their farm lands. If all members of the family could get their farms closer to the family farms, much time and fuel can be saved running between farms. Labor could also be consolidated and work simultaneously on all farms.
Farmers could increase their output and productivity through fertilizer application and pesticide use. With nitrogen and phosphorus deficient soil, more fertilizer rich in these nutrients should be applied. Farmers have used the NPK (1515-15) for a long time. With the availability of the NPK (23-10-5), farmers should be encouraged to use that instead for their maize farms, since it has more nitrogen content. This can be done through extension agents in the districts. More so, the prices of the two compound fertilizers are the same at the subsidized price. As a form of inducement, the subsidy on the NPK (23-20-5) can be increased. This idea will not only increase productivity but improve the already nitrogen and phosphorus deficient soils in the region. Pesticide use according to the results should also be encouraged but it comes with the additional responsibility of controlling its imports and application as its hazards can equally be devastating.

Furthermore, farmers should be trained to consider farming more than just feeding their families. It should be a business. In terms of production, they are relatively better as reflected in the technical efficiency estimate. However, cost minimization is the problem. This means that farmers in the region can easily improve their technical efficiencies and productivities but would find it difficult to improve their incomes, if the business mindset is not applied in the agricultural production. Government should pay attention to pressing challenges outlined especially the tractor services, irrigation and accurate weather prediction equipment to mitigate the effects of rainfall and draught. Ultimately, we recommend similar study in all regions focusing on the crop or crops that directly supports the needs of the population. When an effort is made to increase the productivities and efficiencies of farmers in those regions, it will complement the growing Ghanaian economy, increase food security and reduce the growing income inequality.

\section{ACKNOWLEDGEMENTS}

This research is supported by Çukurova Üniversitesi Bilimsel Araştırma Projeleri Birimi, Adana, Turkey. Project Code: FDK-2015-4029. We also like to thank Burak Öztornaci for his support.

CITATION: Abukari A.B., T. \& Alemdar T. (2019). Measuring the Technical and Cost Efficiencies of Maize Farming in the Northern Region of Ghana: Deterministic and Stochastic Approaches. Agricultural Socio-Economics Journal, 19(1), 47-64. DOI: http://dx.doi.org/10.21776/ub.agrise.2019.019.1.6 


\section{REFERENCES}

Addai KN, Owusu V, 2014. Technical efficiency of maize farmers across various agro ecological zones of Ghana. Journal of Agriculture and Environmental Sciences, 3, 149-172.

Akramov K, Malek M, 2011. Analyzing Profitability of Maize, Rice, and Soybean Production in Ghana: Results of Pam and DEA Analysis. GSSP Working Paper 28. Accra, Ghana: International Food Policy Research Institute

Alemdar T, Ören MN, 2006. Measuring Technical Efficiency of Wheat Production in Southeastern Anatolia with Parametric and Nonparametric Methods. Pakistan Journal of Biological Sciences, V. 9, N. 6, 1088- 1094, 2006.

http://dx.doi.org/10.3923/pjbs.2006.1088.10 $\underline{94}$

Amanor-Boadu V, Zereyesus Y, Ross K, 2015. Agricultural production survey for the Northern Regions of Ghana: 2013-2014 results.

Anang BT, Bäckman S, Sipiläinen T, 2016. Agricultural microcredit and technical efficiency: The case of smallholder rice farmers in Northern Ghana. Journal of Agriculture and Rural Development in the Tropics and Subtropics 117(2): 189-202. http://nbn-resolving.de/urn:nbn:de:hebis:342016061350415

Chapoto A, Sabasi D, Asant-Addo C, 2015. Fertilizer Intensification and Soil Fertility Impact on Maize Yield Response in Northern Ghana. 2015 AAEA \& WAEA Joint Annual Meeting, July 26-28, San Francisco, California, Agricultural and Applied Economics Association \& Western Agricultural Economics Association.

Coelli TJ, Prasada RDS, O'Donnell CJ, Battese GE, 2005. An Introduction to Efficiency and Productivity Analysis, 2nd Edition, Springer, New York, $366 \mathrm{P}$.

Cooke E, Hague S, McKay A, 2016. The Ghana Poverty and Inequality report: Using the 6th Ghana Living Standards Survey. Accra: Art Excel Gh.
Danquah M, Iddrisu AM, 2016. Ghana's long run growth: Policy options for inclusivity and equity. Paper prepared for the African Development Bank, Accra.

Davidson R, MacKinnon JG, 1981. Several Tests for Model Specification in the Presence of Alternative Hypotheses. Econometrica 49(3):781-793

FAO (Food and Agriculture Organization), 2005. Fertilizer Use by Crop in Ghana. International Fertilizer Industry Association (IFA). Land and Water Development Division of FAO.

Ferrier GD, Lovell CAK, 1990. Measuring Cost Efficiency in Banking: Econometric and Linear Programming Evidence. Journal of Econometrics, 46, 229-245. https://doi.org/10.1016/03044076(90)90057-Z

Gelan A, Muriithi BW, 2012. Measuring and Explaining Technical Efficiency of Dairy Farms: A Case Study of Smallholder Farms in East Africa, Agrekon: Agricultural Economics Research, Policy and Practice in Southern Africa, 51:2, 53-74. https://doi.org/10.1080/03031853.2012.6951 $\underline{40}$

GSS (Ghana Statistical Service), 2012. 2010 Population and Housing Census. Summary Report of Final Results.

GSS (Ghana Statistical Service), 2014. Ghana Living Standards Survey (GLSS6) - Main Report

Hjalmarsson L, Kumbhakar S, Heshmati A, 1996. DEA, DFA and SFA: A Comparison. Journal of Productivity Analysis, 7, Pp. 303-327.

http://dx.doi.org/10.1007/BF00157046

Hoff A, 2007. Second Stage DEA: Comparison of Approaches for Modeling the DEA Score. Eur J Oper Res 181:425-435. https://doi.org/10.1016/j.ejor.2006.05.019

Johansson H, 2005. Technical, Allocative, and Economic Efficiency in Swedish Dairy Farms: The Data Envelopment Analysis versus the Stochastic Frontier Approach. The $11^{\text {th }}$ International Congress of The European Association of Agricultural 
Economists (EAAE), Copenhagen, Denmark, August 24-27, 2005

Jones AM, Rice N, Bago T, Balia S, 2013. Applied Health Economics, second edition. London: Taylor and Francis.

Liu JS, Lu LY, Lu WM, 2016. Research Fronts and Prevailing Applications in Data Envelopment Analysis. In: Zhu J. (eds) Data Envelopment Analysis. International Series in Operations Research \& Management Science, vol 238. Springer, Boston, MA

McDonal J, 2009. Using Least Squares and Tobit in Second Stage DEA Efficiency Analyses. Eur J Oper Res 197(2):792-798. https://doi.org/10.1016/j.ejor.2008.07.039

Papke LE, Wooldridge JM, 1996. Econometric methods for fractional response variables with an application to $401(\mathrm{k})$ plan participation rates. J Appl Econ 11(6):619632. https://doi.org/10.1002/(SICI)10991255(199611)11:6\%3C619::AIDJAE418\%3E3.0.CO;2-1

Pregibon D, 1980. Goodness of Link Tests for Generalized Linear Models. Appl Stat 29(1):15-24

Ragasa C, Chapoto A, 2017. Limits to Green Revolution in rice in Africa: The case of Ghana. Land Use Policy 66: 304-321. https://doi.org/10.1016/j.landusepol.2017.04 .052

Ramanathan R, 2003. An Introduction to Data Envelopment Analysis: A Tool for Performance Measurement. Sage Publications, New Delhi.

Ramalho EA, Ramalho JJS, Henriques PD, 2010a. Fractional Regression Models for Second Stage DEA Efficiency Analyses. J Product Anal 2010; 34:239-255. https://doi.org/10.1007/s11123-010-0184-0

Ramalho EA, Ramalho JJS, Murteira J, 2010 b. Alternative Estimating and Testing Empirical Strategies for Fractional Regression Models. J Econ Surv. https://doi.org/10.1111/j.14676419.2009.00602.x
Ritter C, Simar L, 1997a. Pitfalls of NormalGamma Stochastic Frontier Models. Journal of Productivity Analysis 8:2 (May), 167-82. https://doi.org/10.1023/A:1007751524050

Rosen CJ, Bierman PM, Eliason RD, 2008. Soil Test Interpretations and Fertilizer Management for Lawns, Turf, Gardens, and Landscape Plants. University of Minnesota Extension, St Paul, Mn

Shamsudeen A, Paul KN, Samuel AD, 2013. Technical efficiency of maize production in Northern Ghana. African Journal of Agricultural Research, 8, 5251-5259. https://doi.org/10.5897/AJAR2013.7753

Sharma KR, Leung PS, Zaleski HM, 1999. Technical, Allocative and Economic Efficiencies in Swine Production in Hawaii: A Comparison of Parametric and Nonparametric Approaches. Agric Econ 20:23-35. https://doi.org/10.1016/S01695150(98)00072-3

Simar L, Wilson P, 2007. Estimation and Inference in Two-Stage, Semi-Parametric Models of Production Processes. Journal of Econometrics 136, 31-64. https://doi.org/10.1016/j.jeconom.2005.07.0 $\underline{09}$

Silva E, Mendes AB, Santos J, 2013. Efficiency Measures in the Agricultural Sector: The Beginning. In "Efficiency Measures in the Agricultural Sector: With Applications." Mendes, A.B., Soares Da Silva, E.L.D.G., and Santos J.M.A. (Eds.), ISBN: 978-94007-5738-7, Pp. 3-12.

Singh S, Coelli T, Fleming E, 2001. Performance of Dairy Plants in the Cooperative and Private Sectors in India. Annals of Public and Cooperative Economics, 72: 453-479. https://doi.org/10.1111/1467-8292.00178

Wooldridge JM, 2016. Introductory Econometrics: A Modern Approach. Cengage Learning, USA. 


\section{APPENDICES}

\section{Appendix 1: Segregation of soil nutrients and prices in compound fertilizers}

The proportions represent what percentage of the fertilizer is made up of those nutrients. For example, an NPK (15-15-15) fertilizer bag of 50kg contains $15 \%$ nitrogen, $15 \%$ phosphorus, $15 \%$ potassium and $55 \%$ fillers or other ingredients. This therefore means that in terms of weight, the bag contains $7.5 \mathrm{~kg}$ of nitrogen $(15 / 100 * 50)$, $7.5 \mathrm{~kg}$ of phosphorus, $7.5 \mathrm{~kg}$ of potassium and $27.5 \mathrm{~kg}$ of the other ingredients. Let the per unit cost of $\mathrm{N}, \mathrm{P}, \mathrm{K}$ and fillers be $\mathrm{n}, \mathrm{p}, \mathrm{k}$ and $\mathrm{f}$.

For a NPK (15-15-15) which costed GHC 95 in 2014/2015 farming season;

$7.5 * \mathrm{n}+7.5 * \mathrm{p}+7.5 * \mathrm{k}+27.5 * \mathrm{f}=95$

For NPK (23-10-5) fertilizer which also cost GHC 95;

$11.5 * \mathrm{n}+5 * \mathrm{p}+2.5 * \mathrm{k}+31 * \mathrm{f}=95$

For urea (46-0-0) fertilizer which also cost GHC 95

$23 * \mathrm{n}+27 * \mathrm{f}=95$

Ammonium Sulfate (21-0-0) cost GHC 85.

$10.5 * \mathrm{n}+39.5 * \mathrm{f}=85$

Solving these four equations simultaneously, the per-unit cost of nitrogen, phosphorus, potassium and the fillers are GHC 2.33, GHC 3.56, GHC 1.2 and GHC 1.5 respectively. LINGO 14.0 program is used in the estimation

\section{Appendix 2: Simultaneous equations for technically efficient input vector $\left(X^{t}\right)$}

Assuming a Cobb-Douglas production function, the five inputs are represented in Eqn 5. Eqn 6 are the ratios of theses inputs.

$$
\begin{aligned}
& \hat{Y}_{i}=\beta_{0} X_{1}^{\beta_{1}} X_{2}^{\beta_{2}} X_{3}^{\beta_{3}} X_{4}^{\beta_{4}} X_{5}^{\beta_{5}} e^{-u_{i}} \\
& \frac{\mathrm{X}_{1}}{\mathrm{X}_{2}}=\mathrm{R}_{12}, \quad \frac{\mathrm{X}_{1}}{\mathrm{X}_{3}}=\mathrm{R}_{13}, \quad \frac{\mathrm{X}_{1}}{\mathrm{X}_{4}}=\mathrm{R}_{14} \quad \text { and } \frac{\mathrm{X}_{1}}{\mathrm{X}_{5}}=\mathrm{R}_{15}
\end{aligned}
$$

\section{Appendix 3: Duality}

Assuming the production function is dual and assuming Cobb Douglas;

$$
\widehat{\mathrm{Y}}_{\mathrm{i}}=\mathrm{A} \prod_{\mathrm{k}=1}^{\mathrm{k}=5} \mathrm{X}_{\mathrm{k}}{ }^{\beta_{\mathrm{k}}} \mathrm{e}^{-\mathrm{u}_{\mathrm{i}}} \quad \sum_{\mathrm{k}=1}^{\mathrm{k}=\mathrm{K}} \beta_{\mathrm{k}}=\operatorname{rst}\left(\text { Returns to Scale) } \ln \mathrm{A}=\beta_{0}\right.
$$

The corresponding cost frontier would be

$$
C_{i}=A^{*} \prod_{k=1}^{k=5} P_{i k}^{a_{i}} \hat{Y}_{i}^{b_{i}} \quad \ln A^{*}=a_{0}
$$

The formulation for transforming the production function into a cost function is given below;

$$
C_{i}=r s t *\left(A * \prod_{k=1}^{k=5} \beta_{k}{ }^{\beta_{k}}\right)^{-1 / r s t}\left(\prod_{k=1}^{k=5} P_{k}^{\beta_{k}}\right)^{1 / r s t} \hat{Y}^{1 / r s t}
$$

Where; 


$$
A^{*}=r s t *\left(A * \prod_{k=1}^{k=5} \beta_{k} \beta_{k}\right)^{-1 / r s t} \quad a_{i}=\beta_{k} / r s t \quad b_{i}=1 / r s t
$$

Where $\mathrm{P}_{1}, \mathrm{P}_{2}, \mathrm{P}_{3}, \mathrm{P}_{4}$ and $\mathrm{P}_{5}$ represent the per-unit prices of labor, machinery, nitrogen, phosphorous and pesticide, respectively.

\section{Appendix 4: Conditional input demand functions}

These functions represent the demand function for the inputs employed in the analysis. These functions generate the most economically or cost efficient input quantity given their prices and output produced. These are then further used in the estimation of cost and allocative efficiencies.

$$
\begin{aligned}
& \text { Labor: } \\
& \partial \mathrm{C}_{\mathrm{i}} / \partial \mathrm{P}_{1}=\mathrm{X}_{\mathrm{d} 1}=\mathrm{X}_{1}^{\mathrm{c}}\left(\mathrm{P}_{\mathrm{k}}, \widehat{\mathrm{Y}}_{\mathrm{i}}, \delta\right)=0.0004 \mathrm{P}_{1}{ }^{-0.99} \mathrm{P}_{2}{ }^{0.15} \mathrm{P}_{3}{ }^{0.41} \mathrm{P}_{4}{ }^{0.28} \mathrm{P}_{5}{ }^{0.15} \widehat{\mathrm{Y}}^{1.06} \\
& \text { Machinery: } \\
& \partial \mathrm{C}_{\mathrm{i}} / \partial \mathrm{P}_{2}=\mathrm{X}_{\mathrm{d} 2}=\mathrm{X}_{2}^{\mathrm{c}}\left(\mathrm{P}_{\mathrm{k}}, \widehat{\mathrm{Y}}_{\mathrm{i}}, \delta\right)=0.0044 \mathrm{P}_{1}^{0.01} \mathrm{P}_{2}{ }^{-0.85} \mathrm{P}_{3}{ }^{0.41} \mathrm{P}_{4}^{0.28} \mathrm{P}_{5}^{0.15} \widehat{\mathrm{Y}}^{1.06} \\
& \text { Nitrogen: } \\
& \partial \mathrm{C}_{\mathrm{i}} / \partial \mathrm{P}_{3}=\mathrm{X}_{\mathrm{d} 3}=\mathrm{X}_{3}^{\mathrm{c}}\left(\mathrm{P}_{\mathrm{k}}, \widehat{\mathrm{Y}}_{\mathrm{i}}, \delta\right)=0.0126 \mathrm{P}_{1}^{0.01} \mathrm{P}_{2}^{0.15} \mathrm{P}_{3}{ }^{-0.59} \mathrm{P}_{4}{ }^{0.28} \mathrm{P}_{5}{ }^{0.15} \widehat{\mathrm{Y}}^{1.06} \\
& \text { Phosphorous: } \\
& \partial \mathrm{C}_{\mathrm{i}} / \partial \mathrm{P}_{4}=\mathrm{X}_{\mathrm{d} 4}=\mathrm{X}_{4}^{\mathrm{c}}\left(\mathrm{P}_{\mathrm{k}}, \widehat{\mathrm{Y}}_{\mathrm{i}}, \delta\right)=0.009 \mathrm{P}_{1}^{0.01} \mathrm{P}_{2}{ }^{0.15} \mathrm{P}_{3}{ }^{0.41} \mathrm{P}_{4}{ }^{-0.72} \mathrm{P}_{5}^{0.15} \widehat{\mathrm{Y}}^{1.06} \\
& \text { Pesticide: } \\
& \partial \mathrm{C}_{\mathrm{i}} / \partial \mathrm{P}_{5}=\mathrm{X}_{\mathrm{d} 5}=\mathrm{X}_{5}^{\mathrm{c}}\left(\mathrm{P}_{\mathrm{k}}, \widehat{\mathrm{Y}}_{\mathrm{i}}, \delta\right)=0.0046 \mathrm{P}_{1}^{0.01} \mathrm{P}_{2}{ }^{0.15} \mathrm{P}_{3}{ }^{0.41} \mathrm{P}_{4}{ }^{0.27} \mathrm{P}_{5}{ }^{-0.85} \widehat{\mathrm{Y}}^{1.06}
\end{aligned}
$$

\section{Appendix 5: Input Allocative Efficiency Coefficient (IAEC)}

An input is allocatively efficient when the cost of increasing that input is equal to the amount of revenue or the value the corresponding output increase would produce (Grazhdaninova and Lerman 2005). This represents the first order condition for profit maximization or the economic optimum of any firm.

The value of the corresponding increase in output is the value of the marginal product (VMP) of the input in question. That is, price of output $\left(\mathrm{P}_{\mathrm{Y}}\right)$ multiplied by the marginal product (MP) of the input in question. Assuming a Cobb-Douglas production function;

$$
\begin{gathered}
M P_{i}=\beta_{\mathrm{i}} * \frac{\bar{Y}}{\bar{X}_{i}} \\
\text { Therefore VMP; } \\
V M P_{i}=\left(\beta_{\mathrm{i}} * \overline{\bar{Y}}\right) * P_{Y}
\end{gathered}
$$

$\beta_{\mathrm{i}}$ is the output elasticity of the input in question; $\bar{Y}$ and $\bar{X}_{i}$ are geometric means of the maize output and the inputs respectively. The logarithmic nature of the production function and the data necessitates the use of geometric means, that is, the mean of natural logarithms. On the other hand, since farmers are price takers, the cost of increasing an additional input is the per-unit price of that input $\left(\mathrm{P}_{\mathrm{i}}\right)$, which is approximated as the Marginal Factor Cost (MFC) (Grazhdaninova and Lerman 2005). That is $\mathrm{MCF}_{\mathrm{i}}=\mathrm{P}_{\mathrm{i}}$. This therefore means that an input ' $i$ ' is allocatively efficient when;

$$
\left(\beta_{\mathrm{i}} * \frac{\overline{\mathrm{Y}}}{\bar{X}_{i}}\right) * P_{Y}=P_{i} \quad \text { or } \quad \operatorname{VMP}_{i}=P_{i}
$$

This equation is rearranged by dividing both sides by Pi to give the coefficient or index in Equation 42 


$$
\text { IAEC }=\frac{\beta_{\mathrm{i}} *\left(\overline{\mathrm{Y}} / \bar{X}_{i}\right) * P_{Y}}{\mathrm{P}_{\mathrm{i}}} \quad \text { or } \quad M P_{i} * \frac{P_{Y}}{\mathrm{P}_{\mathrm{i}}}
$$

At an economic optimum or maximum profit, this coefficient should be equal to 1, implying the input is allocatively efficient. It does not require any change to its current quantity. If it is less than 1 , the input is excessively used and should be reduced. If it is greater than 1, the said input is underutilized and should be increased. 